NOTES

I Health Advisory Service, The Rising Tide. London, 1982.

2 Macdonald, A. J. D., Mann, A. H., Jenkins, R., Richard, L., Godlove, C. and Rockwell, G., An attempt to determine the impact of four types of care upon the elderly in London by the study of matched groups. Psychological Medicine, 12 (1982), 193-200.

3 Blessed, G., Tomlinson, B. E. and Roth, M., The association between quantitative measures of dementia and of senile change in the grey matter of elderly subjects. British Joumal of Psychialry, 114 (1968), 797-811.

4 Robinson, R. A., The organisation of a diagnostic and treatment unit for the aged in a mental hospital. In: Psychiatric Disorders in the Aged, World Psychiatric Association, 1965, 186-193.

5 Wilkin, D., Mashiah, T. and Jolley, D. J., Changes in behavioural characteristics of elderly population of Local Authority homes and long-stay hospital wards 1976-77. British Medical Journal, 2 (1978), 1 $274^{-1} 276$.

6 Schiphorst, B. Report of a Dependency Survey of the Elderly in Stockton on Tees Borough. North Tees Health Authority, 1980.

7 Meacher, M. Taken for a Ride: Special Residential Homes for Confused Old People: A Study of Separatism in Social Policy. Longman, London, 1972.

Health Care Research Unit, University of Newcastle upon Tyne.

\title{
Demography and migration
}

\section{Tony Warnes}

D. T. Rowland, 'Old age and the demographic transition' Population Studies, $3^{8}$ (1984), 73-87.

This paper is a product of research into 'Ageing and the Family' at the Australian National University. By presenting a set of tabulations drawn from successive censuses and from a social survey of elderly people in Sydney in I98 $\mathrm{I}$, this article examines the changes in selected demographic, household and familial characteristics among the Australian population over the last seventy years. It reflects the growing interest in ageing issues in that country and it adds usefully to the evidence concerning elderly people's changing living arrangements and availability of kin in demographic regimes of low fertility and mortality. Despite this title, the article does not adopt theoretical or comparative objectives with respect to the demographic transition: the term is used simply to describe the decline in fertility and mortality during the last century.

Among the many detailed findings of interest, it is shown that changes in family size during the demographic transition have had only a small 
impact upon the supply of potential carers among relatives, since the average number of sons and daughters surviving to age 60 has not varied substantially over time. However, the potential demand for family support has grown considerably as a result of increases in the proportions surviving to old age.

The 198 i social survey collected information concerning the persons living with the elderly respondents when (between rgo I and I93 I) they were ten years old, as well as the extent to which their own parents were insufficiently healthy to manage on their own after 60 years of age. Allowing for an overlap between old age and the 'child launching' stage of the life cycle, it is shown that the majority of the respondents' parents did not enter into joint living arrangements with their children in later life. Moreover, the short duration of many joint households suggests that these were contingency arrangements typical only near the end of a parent's life, rather than being characteristic throughout old age. Co-residence for the purpose of assisting an aged parent typically begins after a son's or a daughter's children have left the parental home.

The article also discusses the impacts of mortality and fertility decline, fluctuating childlessness and changing co-residence with siblings and other relatives upon the social situation of the older population. The average number of sons and daughters surviving through their parents' old age has not varied greatly because falling death rates compensated for fertility decline. It is also suggested that extended family households have never been important in Australia. The final paragraphs focus on the projections for the next two decades of the numbers of persons aged 75 years or more. Attention is also given to the changing European origins of this elderly population. Rowland concludes that, 'compared with the aged in the rg7os and the r99os, the aged cohorts during the present decade will be relatively deprived in terms of potential access to the assistance of off-spring'.

C. M. S. Concord, 'A mover/stayer approach to residential mobility of the aged'. Tijdschrift voor Econ. en Soc. Geografie, 75 (1984), $249-62$.

Since the early I 970 in Britain, France, north America and Australia, many studies have been conducted from contrasting perspectives into the residential mobility or migration of the elderly. In recent years signs have become evident of a welcome interchange between social gerontological, behavioural and demographic modelling interests: these should lead to enhanced and more complex understandings. This article reviews United States research into interstate and intraurban migration 
by older persons and presents results from a multivariate analysis of special cross-tabulations from the 1975 Bureau of the Census's Current Population Survey of mobility during $1970-75$.

The paper begins by identifying some consistent results from previous research and accepts that the many discrepancies stem in part from different levels of data disaggregation. The limitations of bivariate approaches are exposed and the case is made for multivariate categorical data analysis using logit methods. Attention is focussed restrictingly on moves by the white population within metropolitan regions (strictly SMSAs), while the opportunity given by the US census data to model separately short, medium and long distance moves is not taken up. On the other hand, six factor or 'independent' variables are analysed; viz age trichotomised to $55^{-6}, 65^{-74}$ and $75+$ years; sex; education of the household head ( 3 categories); household type (5 categories differentiating the sex of the household head or heads and the presence or absence of others); employed or unemployed; total income and unearned income (both in 3 categories). All possible interactions between the 'effect variable', the logarithm of the probability of moving, and the six factor variables are considered.

Logit analysis employs a stepwise or hierarchical procedure from a saturated model in which all factors and interactions are included. In the study two models, separating total income from unearned income, are examined. In both cases the association between mobility and all the independent factors are required to adequately represent the observed frequencies, but no interactions relating three or more factors with mobility improved the models' predictions. The analytical task was thus reduced to determining which, if any, of the three variable interaction terms were required.

The discussion of the results is detailed and given the intricacy of the material clearly developed and written. For the unearned income model, one three variable interaction emerges strongly, that between unearned income, household type and the probability of moving. For the total income model, three interactions of similar importance are identified: between mobility and $(a)$ age and income, $(b)$ education and household type, and $(c)$ income and household type. Several sample logits are presented to demonstrate the importance of household type in enhancing or reducing the likelihood of moving when holding other characteristics constant. Each household type showed distinctive interaction patterns such that no two could be combined.

This finding leads the author to fit optimal models for each household type and her further interpretation focuses on married couple households and females living alone. For the former the overall probability of 
moving is 0.24 : it is raised if the household head is employed, or of higher education, while it declines with increasing age and total income. The only more complex interaction which has to be added is that between labour force status, income and mobility. Among the many other results, it is summarised that better educated persons tend to have higher income in employment which produces higher transfer income upon retirement, all of which encourages the residential stability of married couple households.

The analysis of the residential mobility of older women who live alone also finds that the level of income is of critical importance and leads Stapleton into a fascinating discussion about the income-paths of older people as they or their spouses cease employment or are widowed. Among the situations which are considered is the extent to which labour force participation covaries with income, the possibility of cohort distinctions between the three age groups and, more interpretatively, the implications for widows' incomes of the tendency for men to marry women of lower educational attainment. The article concludes with clear methodological recommendations; that further understanding of the residential decision processes of aged households will require separate analyses by household type, and that many of the most interesting questions can only be tackled by longitudinal studies.

It is an ambitious and original application of a powerful analytical procedure. Not all the immense difficulties associated with writing a clear interpretation of a host of numerical results have been surmounted but, apart from some unfortunate typographical errors in the setting out of the models and the labelling of variables, Clare Stapleton Concord has written clearly for a non-statistical readership. The paper is packed with findings and intelligent speculation and should raise the sights of all interested in understanding the highly variable mobility behaviour of older people.

King's College, London

\section{Geographical and environmental factors Tony Warnes}

G. D. Rowles, Geographical dimensions of social support in rural Appalachia. In Rowles, G. D. and Otha, R. J. (eds), Aging and Milieu: Environmental Perspectives on Growing Old. Academic Press, 1983, I I I -30 .

This article discusses a participant-observation study of I 5 elderly residents of a declining northern Appalachian mountain town. The 